\title{
The Internal Rate of Return Model for Life Insurance Policies
}

\author{
Prof. Mihir Dash \\ Department of Quantitative Methods \\ School of Business, Alliance University \\ Chikkahagade Cross, Anekal, Bangalore, India-562106 \\ Tel: 91-995-182-465Ｅ-mail: mihirda@rediffmail.com
}

Received: June 20,2016 Accepted: Sep. 10, $2016 \quad$ Published: December 1, 2016

doi:10.5296/ajfa.v8i2.9721 URL: http://dx.doi.org/10.5296/ajfa.v8i2.9721

\begin{abstract}
Life insurance policies are no longer seen solely as a means of insuring life. Due to many new features introduced by life insurers, they are seen in the new light of serving savings and even investment purposes besides the basic purpose of insuring life. The present study discusses the rates of return given by different types of policies, and the effect of mortality on these rates of return across age, sum assured, and maturity period in each type of policy studied.

The findings indicate that different types of policies give different rates of return and that mortality does have an effect on the rates of return. Endowment plans have higher rate of return with mortality incorporated, while for unit-linked investment plans, the rate of return is higher when it is treated purely as an investment instrument. The study also revealed that the unadjusted and mortality-adjusted rates of return follow a linear relationship that is very similar to the capital asset pricing model. The study opens a further scope of research by extending the methodology to include other relevant risk factors besides mortality, and for different types of policies across companies.
\end{abstract}

Keywords: life insurance policies, rate of return, mortality, sensitivity, endowment plans, unit-linked investment plans, capital asset pricing model. 


\section{Introduction}

The life insurance market has over time become more dynamic. In the current scenario, life insurance is no longer seen solely as a means of insuring life. Due to many changes and new features introduced by life insurers, life insurance policies are being seen in the new light of serving the purpose of savings and even investment besides the basic purpose it serves of insuring life.

In any life insurance contract, the rate of return forms an integral element both for the investor and for the life insurer. It is in the interest of both the parties to get some favourable returns from their contract. A life insurance contract involves many contingencies and risks, mortality being one of the major ones among them. The effect that mortality will have on rates of return is therefore an area of great interest in a life insurance contract. It is therefore of relevance to study the rates of return under two conditions: firstly, when the life insurance policies are treated purely as investment instruments, and, secondly, when the probabilities of mortality are incorporated in computing the rates of return. It also becomes an area of interest to study how much these rates of return are sensitive to mortality.

Insurance pricing has a very long history, and discounted cash flow models, along with the internal rate of return approach, are at the heart of most insurance pricing models. Teufel et al (2001) reviews these models in their discussion of the principles of insurance and the risks faced by life insurers. They have listed mortality as one of the major risks and they have called it the "bedrock in the growth and development of the life insurance industry." According to the article, the various factors that enter into the pricing process of insurance policies are: the probability of mortality, the time value of money, the benefits promised, the expenses, and the possible contingencies/ scenarios. The article also discusses risk spreading activities and investment portfolio management.

Feldblum (1992) discussed how financial models which consider the time value of money, surplus commitments and investment income are increasingly being used in insurance ratemaking. He showed how an internal rate of return model can be used to price insurance policies and discusses the framework of the IRR model. He also discussed how insurance transactions may be examined from two points of view as follows: between the policyholder and the insurer (wherein the policyholder pays premiums to purchase an insurance contract, obligating the insurer to compensate the policyholder for incurred losses), and between the equity provider and the insurer (wherein equity providers invest funds in an insurance company, and this investment is expected to provide a return, whether of capital accumulation or dividends). The author then explains how these two viewpoints are interrelated.

The present study also uses a discounted cash flow model, along with an internal rate of return approach, but does not focus on pricing issues as such. Instead, the study envisages the rate of return as a characteristic which can be used to understand life insurance policies and to make comparisons between different types of life insurance policies. The present study discusses the different rates of return given by different types of policies and how the probability of mortality has an effect on these rates of return across different ages for 
different levels of sum assured and maturity periods. The study compares the unadjusted and mortality-adjusted rates of return in all the different categories, and analyses the relationship between the mortality-adjusted rate of return and the unadjusted rate of return. The study also analyses the degree of sensitivity of the rates of return to mortality, and proposes a model for the relationship between the mortality-adjusted rate of return and the unadjusted rate of return.

\section{Data and Methodology}

The data for the study covers three life insurance policies of Kotak Mahindra Old Mutual Life Insurance Limited, viz. the Capital Multiplier Plan, the Money Back Plan, and the Flexi-Plan assuming $8 \%$ and $10 \%$ growth. The study was conducted at five different levels of sum assured of Rs. 1 Lakh, Rs. 2 Lakhs, Rs. 3 Lakhs, Rs. 4 Lakhs, and Rs. 5 Lakhs, with three different maturity periods of 15 years, 20 years, and 25 years. The premia and maturity values of these policies were collected using premium calculators provided by the company. The mortality rates used in the study were collected from LIC mortality tables.

The study involved the calculation of the unadjusted rate of return and mortality-adjusted rate of return. In both the cases, the net present value (NPV) was formulated, and the internal rate of return (IRR), at which the NPV is zero, was then calculated. The NPV formulation differs in the two cases, which may be explained as follows.

\section{Calculation of the unadjusted rate of return:}

In the formulation of NPV for the unadjusted rate of return, the effect of mortality is ignored, and hence life insurance policies are treated purely as investment instruments. The underlying assumption here is that in each case, the individual survives until the maturity of the policy. Therefore, taking the discount factor into account, the calculation of NPV takes the form of the present value of annuity. The formula may be expressed as follows:

$$
N P V=-\sum_{j=1}^{n} \frac{P}{r} \cdot\left[1-\frac{1}{(1+r)^{j}}\right]+\frac{M V}{(1+r)^{n}},
$$

where $P$ denotes the premium, $M V$ the maturity value, $r$ the rate of return, and $n$ the maturity period. The unadjusted rate of return is then calculated by equating the NPV to zero.

\section{Calculation of the mortality-adjusted rate of return:}

In the formulation of NPV for mortality-adjusted rate of return, the effect of mortality is taken into account. Mortality-adjusted rate of return basically means IRR with probabilities of mortality incorporated in the NPV formula. The underlying assumption here is that life is uncertain and hence, mortality constitutes an important element of life insurance policies. The formula used for the expected net present value may be expressed as follows, for a person aged $k$ at the time of entering into the contract:

$$
E(N P V)=-\sum_{j=1}^{n} \frac{P}{(1+r)^{j}} \cdot p_{j}^{(k)}+\frac{M V}{(1+r)^{n}} \cdot p_{n}^{(k)}+\sum_{j=1}^{n} \frac{M V_{j}}{(1+r)^{j}} \cdot q_{j}^{(k)},
$$




\section{Macrothink}

where $P$ denotes the premium, $M V$ the maturity value, $M V_{j}$ the maturity value in year $\mathrm{j}, p_{j}{ }^{(k)}$ the probability that a person aged $k$ will survive for another $j$ years, and $q_{j}{ }^{(k)}$ the probability that a person aged $k$ will survive $j-1$ years but not $j$ years,

$$
\begin{gathered}
p_{j}^{(k)}=p_{k} \times p_{k+1} \times p_{k+2} \times \ldots \ldots \times p_{k+j-1}=\prod_{i=0}^{j-1} p_{k+i}, \\
q_{j}^{(k)}=p_{k} \times p_{k+1} \ldots \ldots p_{k+j-2} \times\left(1-p_{k+j-1}\right)=\left(\prod_{i=0}^{j-2} p_{k+i}\right)\left(1-p_{k+j-1}\right),
\end{gathered}
$$

and where $p_{i}$ is the probability that a person aged $i$ will survive for age $i+1$ (i.e. the age-specific survival rate). The mortality-adjusted rate of return is the calculated by equating the ENPV to zero.

This is applicable for all the types of policies chosen for the study, except for the Money Back Plan. A distinguishing feature of the Money Back Plan is that there are payouts every five years till the maturity date. Taking this into consideration, the payouts are deducted (keeping the discount factor in mind) while calculating both the unadjusted and mortality-adjusted rates of return.

\section{Findings}

The unadjusted and mortality-adjusted rates of return were calculated for each type of policy for different maturity periods of 15 years, 20 years and 25 years and at different levels of sum assured of Rs. 1 lakh, Rs. 2 lakhs, Rs. 3 lakhs, Rs. 4 lakhs and Rs. 5 lakhs across different ages. A comparison was then made separately for unadjusted rate of return and mortality-adjusted rate of return in terms of sum assured, in terms of the products, and finally in terms of maturity period. Finally, for each type of policy, a comparison is made between the unadjusted rate of return and mortality-adjusted rate of return.

\section{By Sum Assured}

The series of graphs which follow present a comparison of the rates of return for each policy at different maturity periods in terms of the sum assured: 

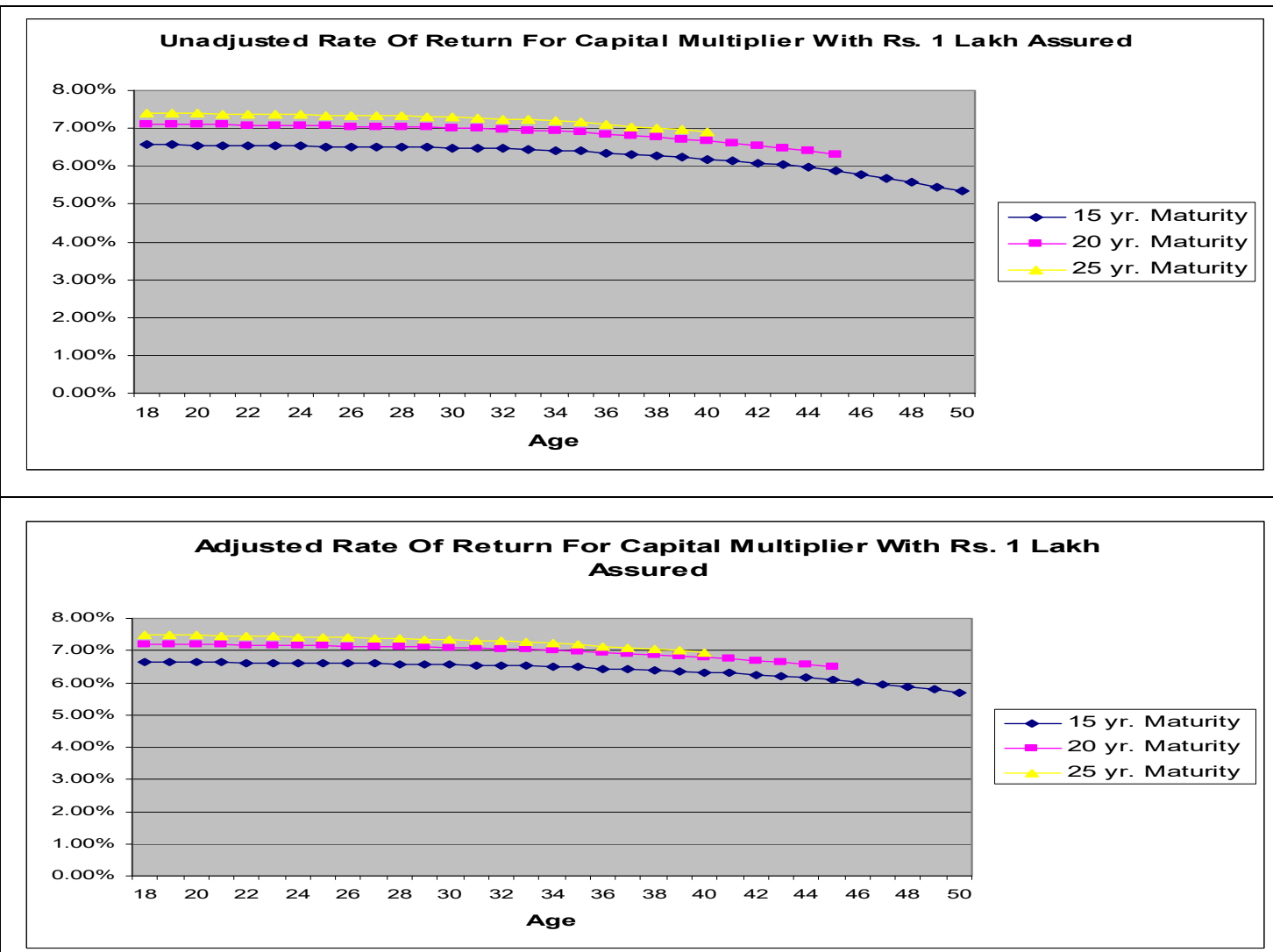

The unadjusted and adjusted IRR curves for the Capital Multiplier Plan are observed to follow similar patterns, at different levels of sum assured, and across different maturity periods. The IRR curves slope downwards, indicating that the rates of return gradually decrease at an increasing rate with age. Further, it is observed that higher maturity periods give higher rates of return, and that the adjusted rates of return are higher than the unadjusted rates of return. 


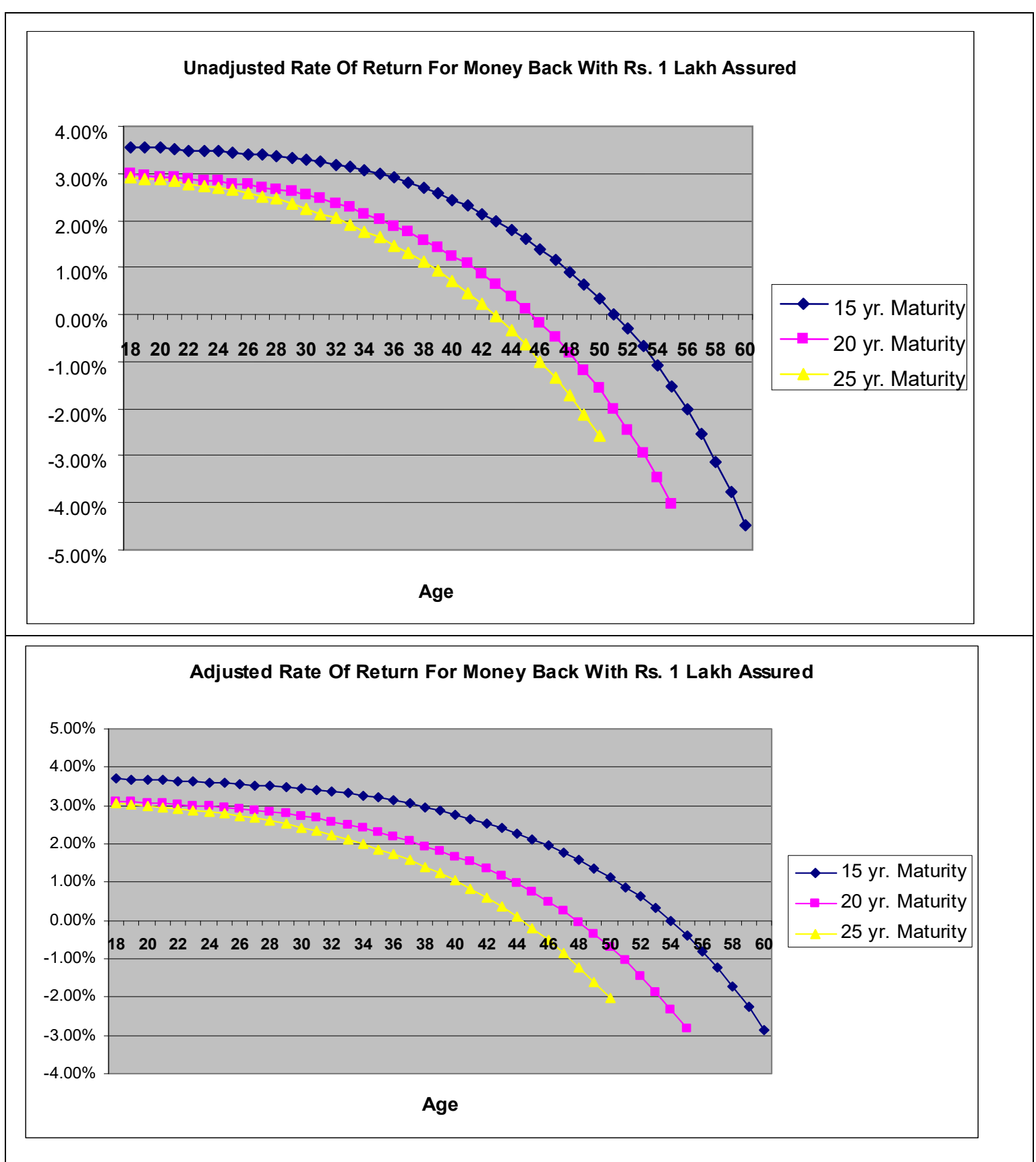

The unadjusted and adjusted IRR curves for the Money Back Plan are observed to follow similar patterns, at different levels of sum assured, and across different maturity periods. The IRR curves slope downwards, the slope being much steeper than in the case of the Capital Multiplier Plan, indicating that the rates of return decrease at a faster rate with age than in the case of the Capital Multiplier Plan. Also, in case of the Money Back Plan, the rates of return become negative at certain ages. Further, it is observed that lower maturity periods give higher rates of return, and that the adjusted rates of return are higher than the unadjusted rates of return. Finally, the rate of decrease of the adjusted rates of return is lower than that of the unadjusted rates of return. 


\section{Macrothink}

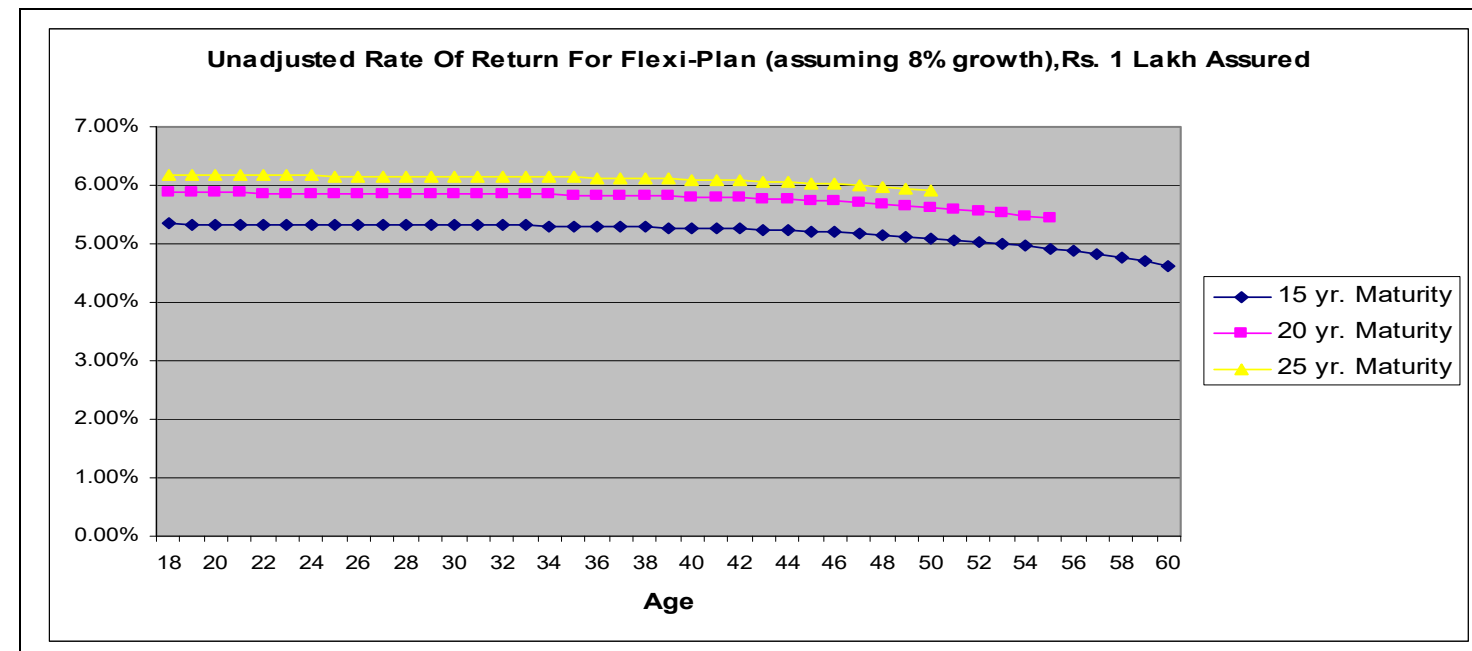

Adjusted Rate Of Return For Flexi-Plan (assuming 8\% growth),Rs. 1 Lakh Assured

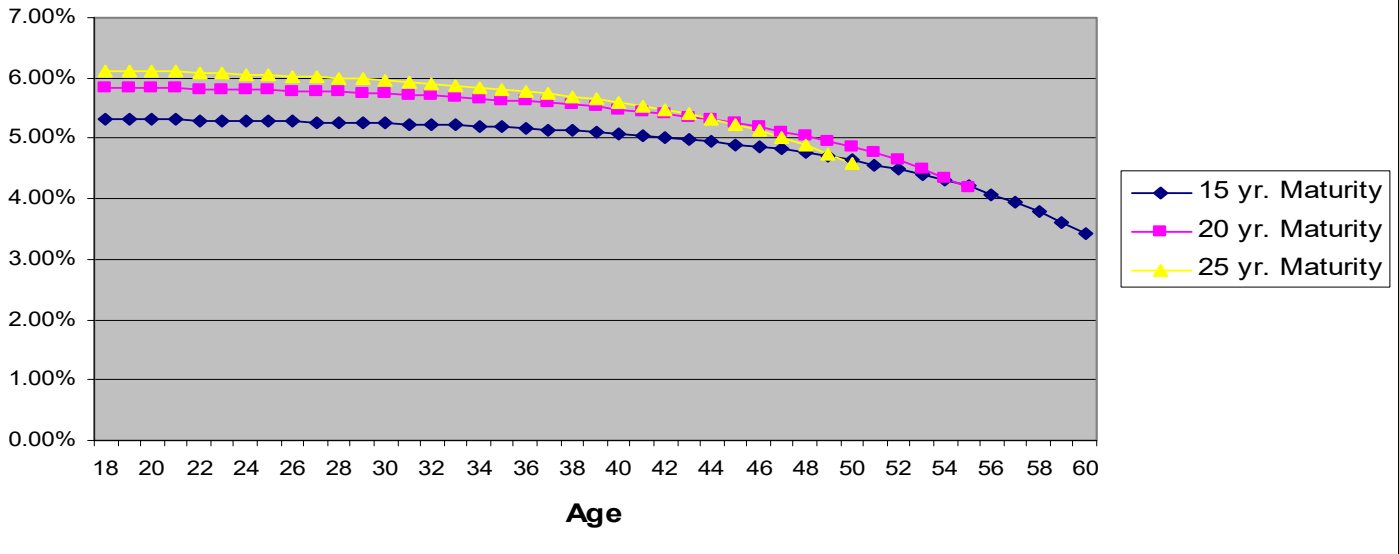

The unadjusted IRR curves for the Flexi-Plan (assuming 8\% growth) are observed to follow similar patterns, at different levels of sum assured, and across different maturity periods. It is observed that higher maturity periods give higher unadjusted rates of return, and that the rate of decrease of the unadjusted rates of return decreases with maturity period. For this policy, the adjusted IRR curves do not follow the same pattern as those of the unadjusted IRR curves. The adjusted IRR curves at 15, 20 and 25 year maturity periods start at different levels, gradually decrease and then coincide at a later stage, indicating that the rate of decrease of the adjusted rate of return increases with maturity period. Also, the adjusted rates of return are observed to be lower than the unadjusted rates of return, indicating that the Flexi-Plan is more of an investment plan than the previous plans. Finally, the rate of decrease of adjusted rates of return is higher than that of unadjusted rates of return. 

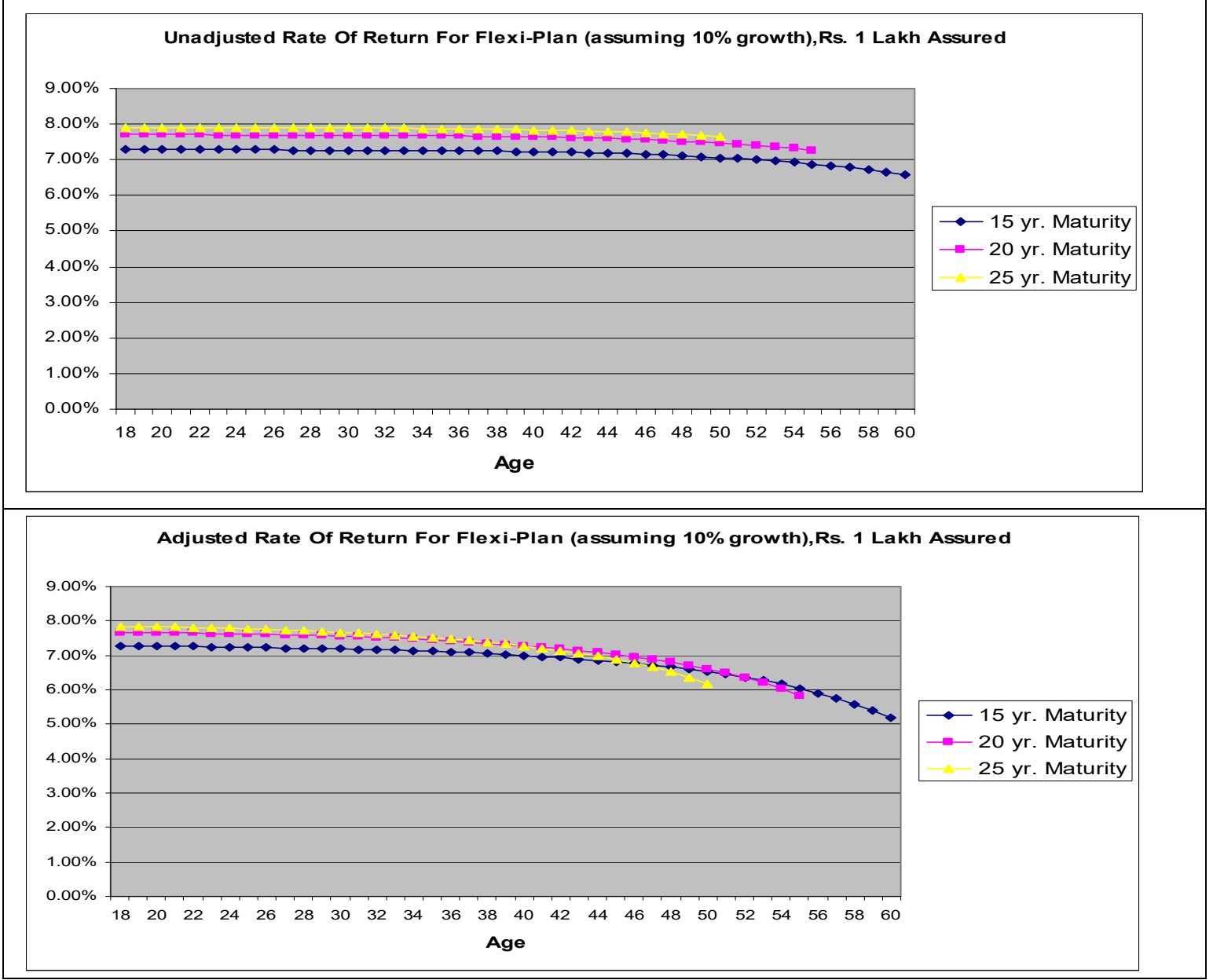

The IRR curves for the Flexi-Plan (assuming 10\% growth) are observed to follow similar patterns as those of the Flexi-Plan (assuming $8 \%$ growth). The unadjusted and adjusted rates of return for the former are all uniformly higher than for the latter.

\section{By Product}

The series of graphs which follow present a comparison of the rates of return at different levels of sum assured and at different maturities in terms of the products:

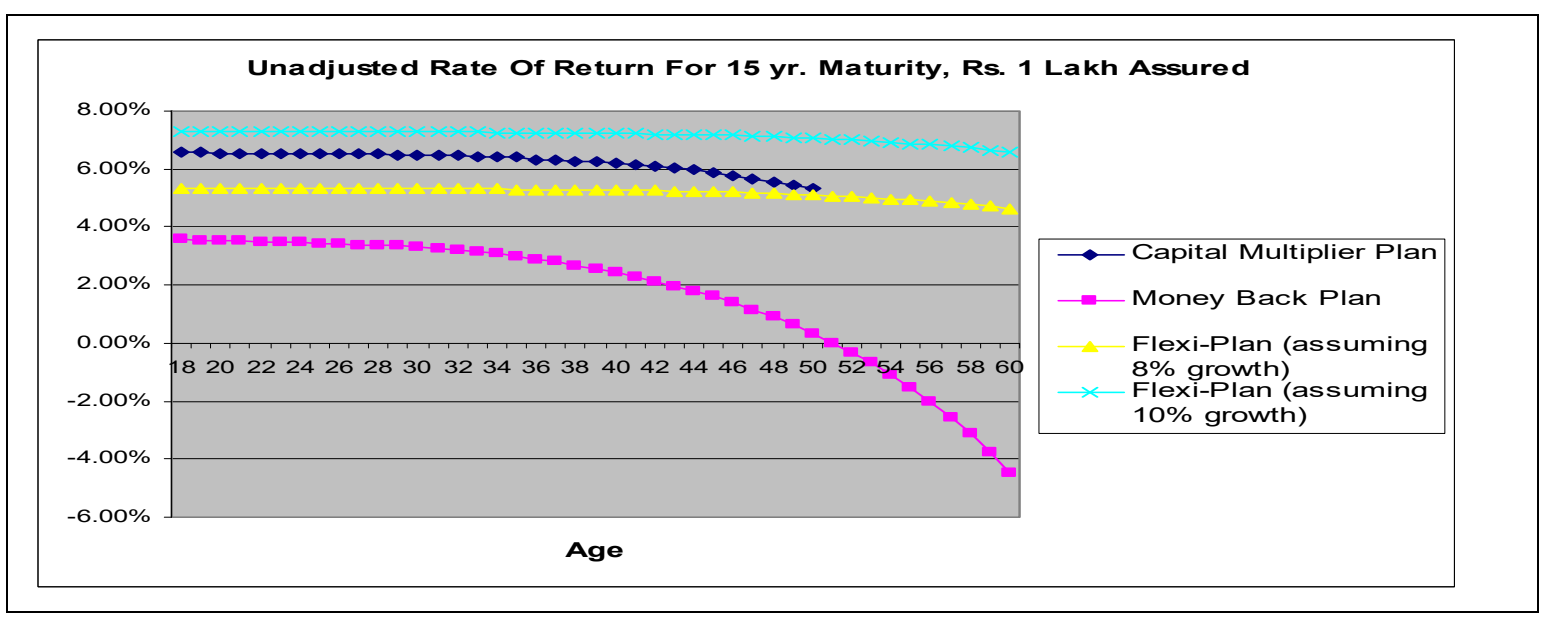



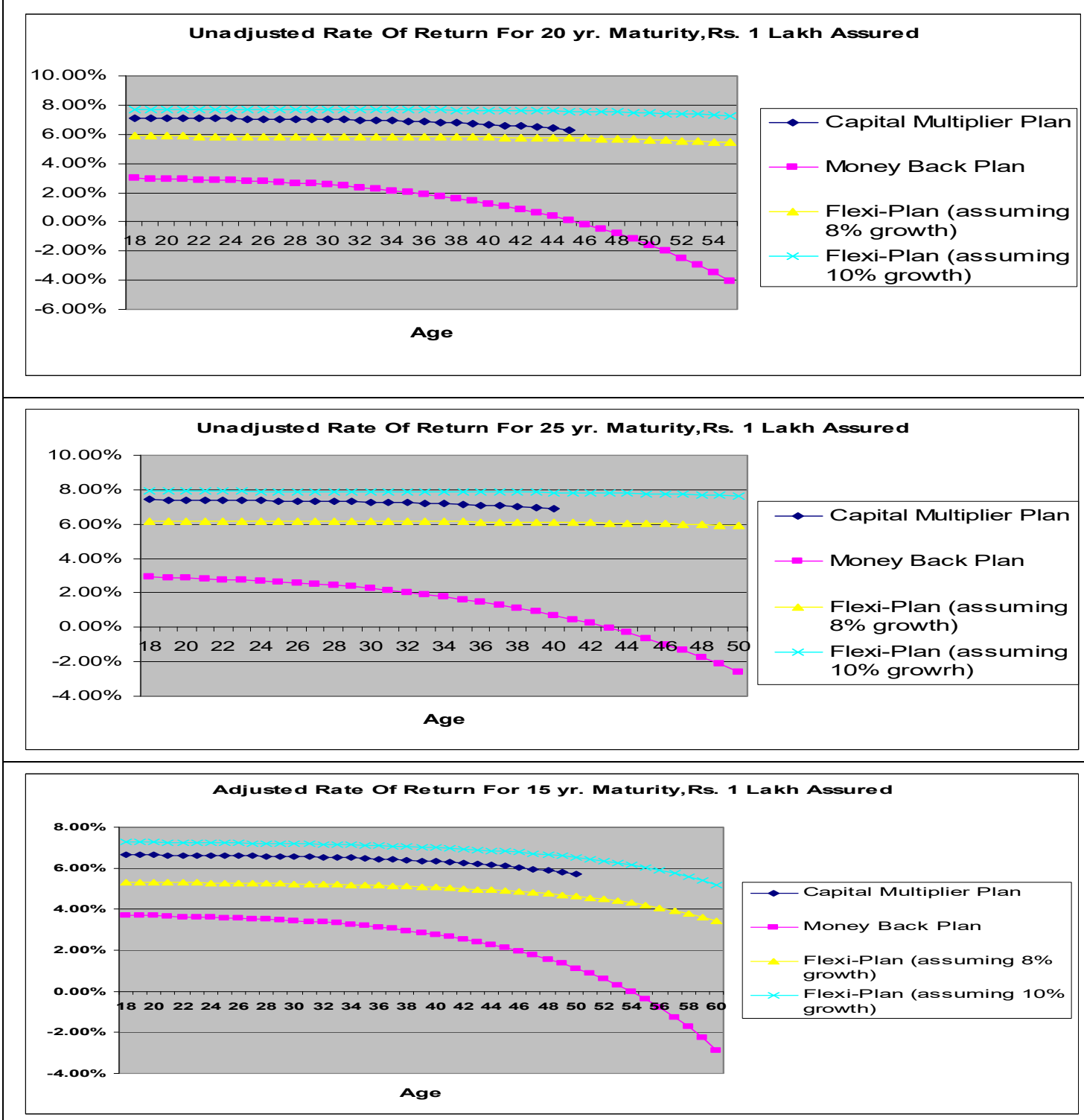

Adjusted Rate Of return For 20 yr. Maturity,Rs. 1 Lakh Assured

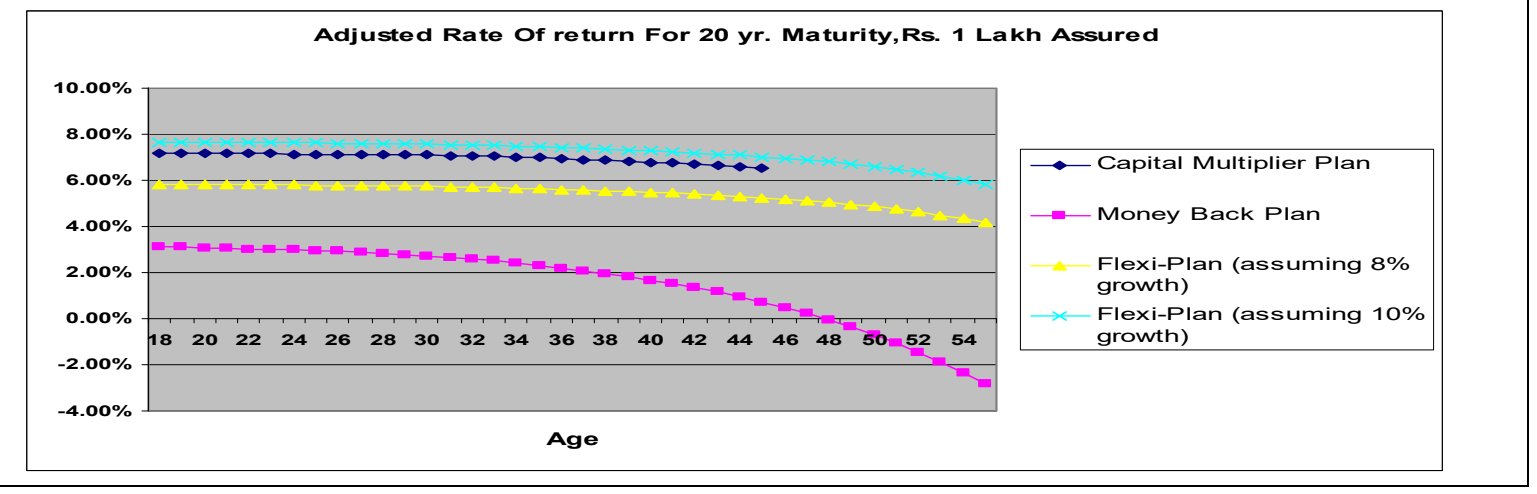




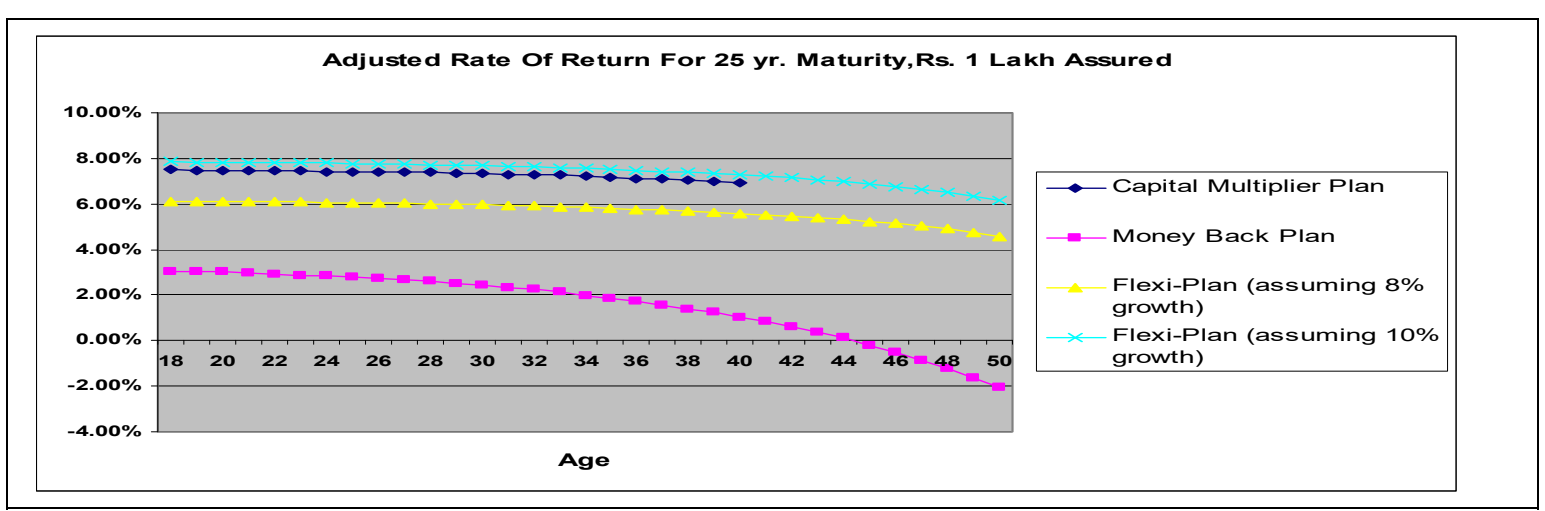

The unadjusted and adjusted IRR curves are observed to follow similar patterns, at different levels of sum assured, and across different maturity periods, the only difference being that for the Flexi-Plan (both cases), adjusted IRR curves have a much steeper slope than in the case of unadjusted IRR, indicating that the rate of decrease of the rates of return is higher for the adjusted rates of return than for the unadjusted rates of return. The Flexi-Plan (assuming 10\% growth) is observed to have the highest rate of return, followed by the Capital Multiplier Plan and then the Flexi-Plan (assuming 8\% growth), while Money Back Plan is observed to have the lowest rate of return. The IRR curves of the Flexi-Plan (assuming 8\% growth) and Flexi-Plan (assuming 10\% growth) are parallel to each other, indicating that plans of the same type show a similar pattern: their IRR curves are constant almost throughout, with only a slight rate of decrease before the maximum age. The Capital Multiplier Plan has a gradual slope, indicating that the rate of return gradually decreases with age. The Money Back Plan has the steepest slope. The rate of decrease of the rates of return in this case is fast, and the rates of return become negative at certain ages.

\section{III.By Maturity Period}

The series of graphs which follow present a comparison of the rates of return for each policy at different levels of sum assured in terms of the maturity periods:

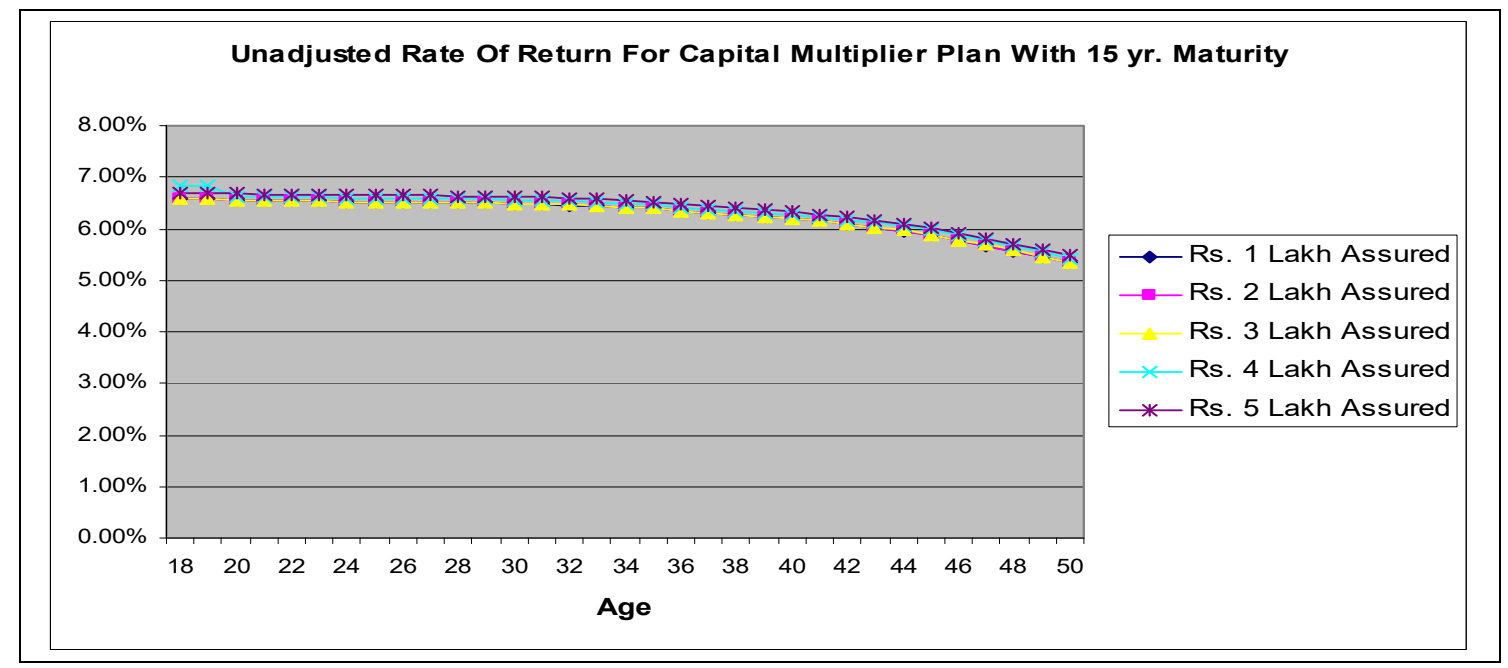



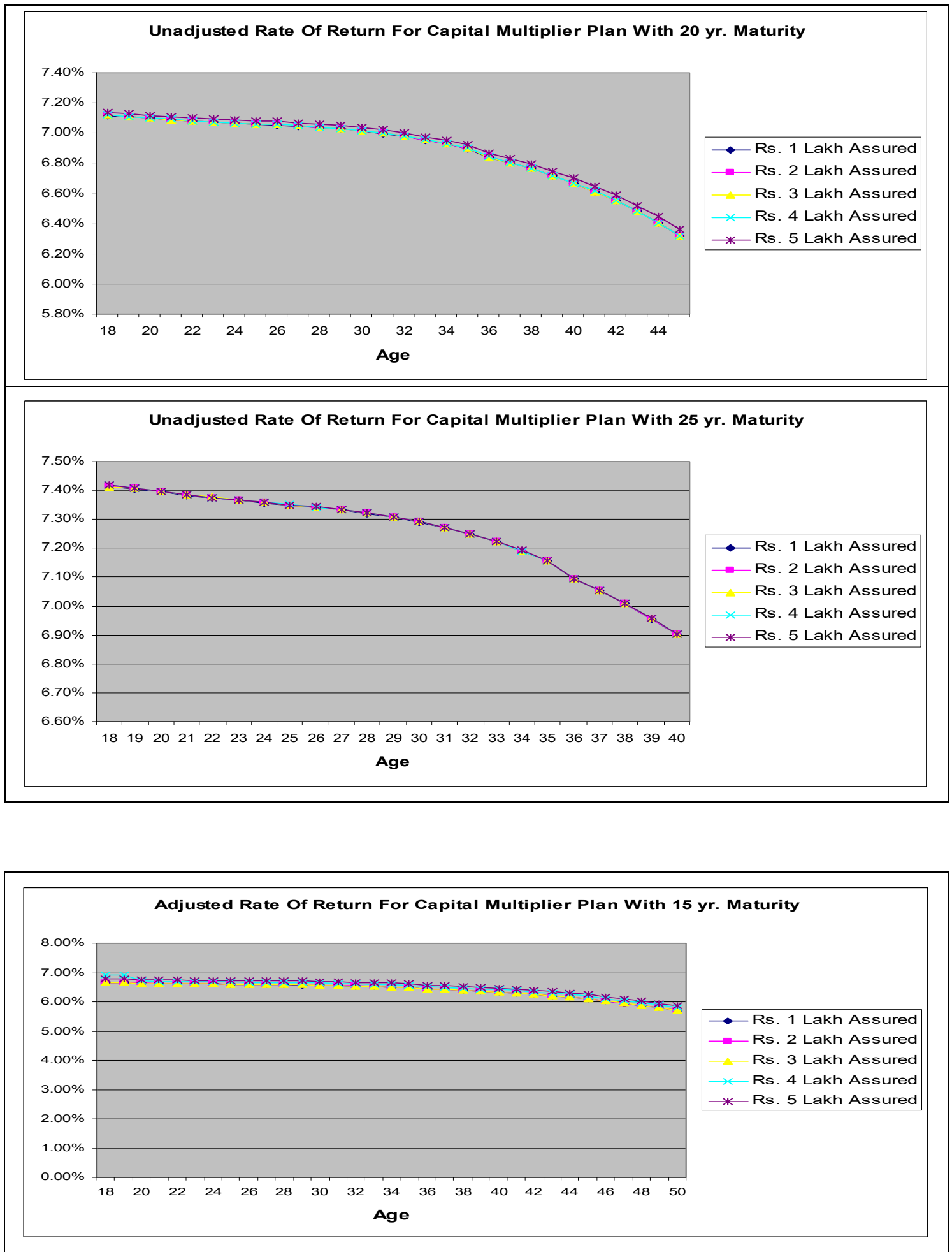


\section{Macrothink}

Asian Journal of Finance \& Accounting

ISSN 1946-052X

2016, Vol. 8, No. 2
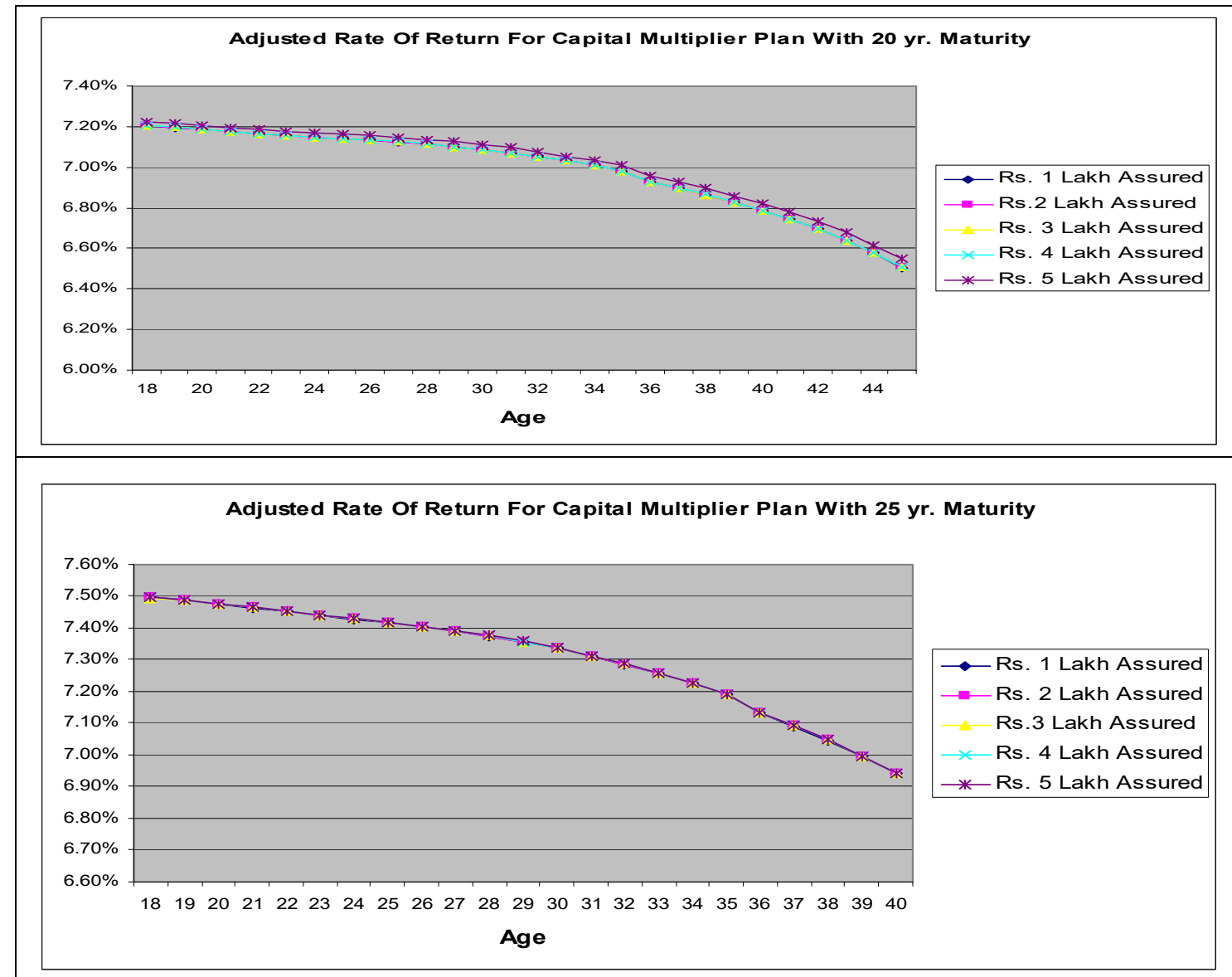

As noted before, the unadjusted and adjusted IRR curves for the Capital Multiplier Plan are observed to follow similar patterns, at different levels of sum assured, and across different maturity periods. It is observed that the IRR curves all coincide together, indicating that the rate of decrease of rates of return with age at different levels of sum assured is more or less uniform in all the cases. Also, the IRR curves at 20 and 25 year maturity periods have a steeper slope, indicating that the rate of decrease in rates of return with age increases with maturity period.

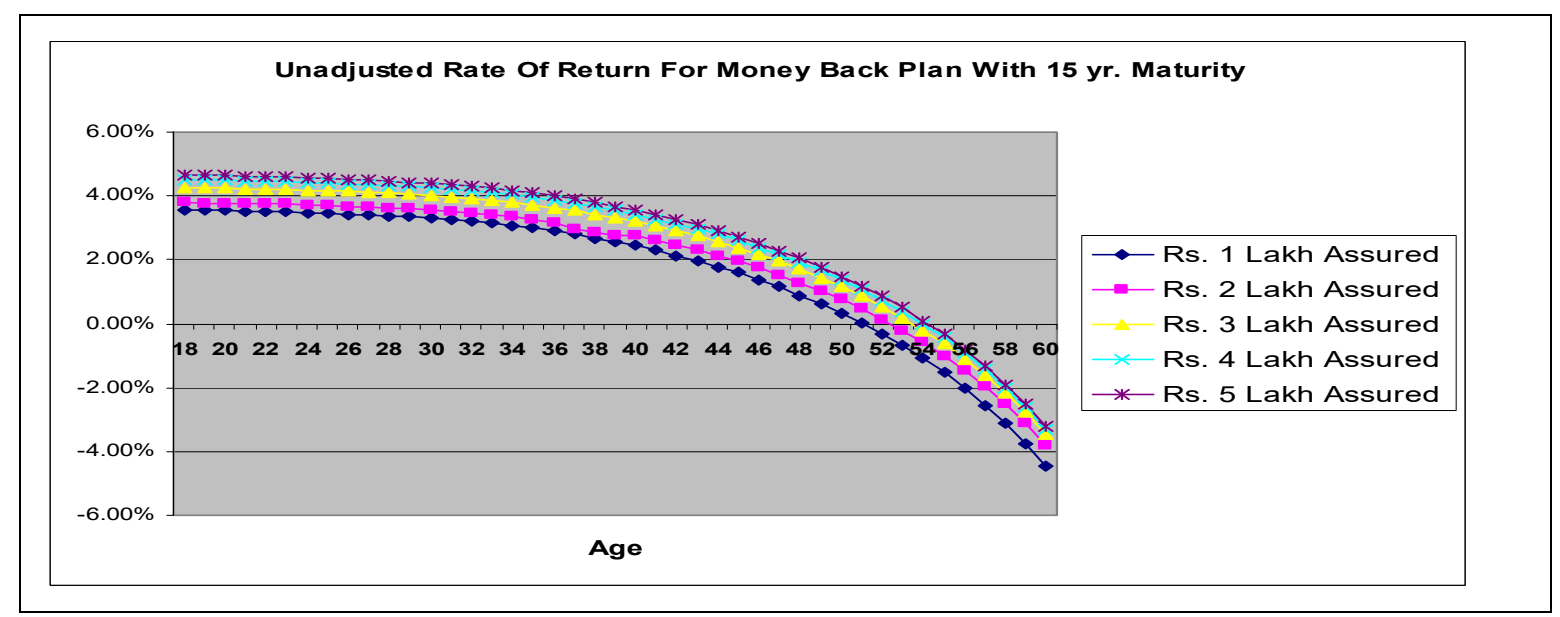




\section{Macrothink

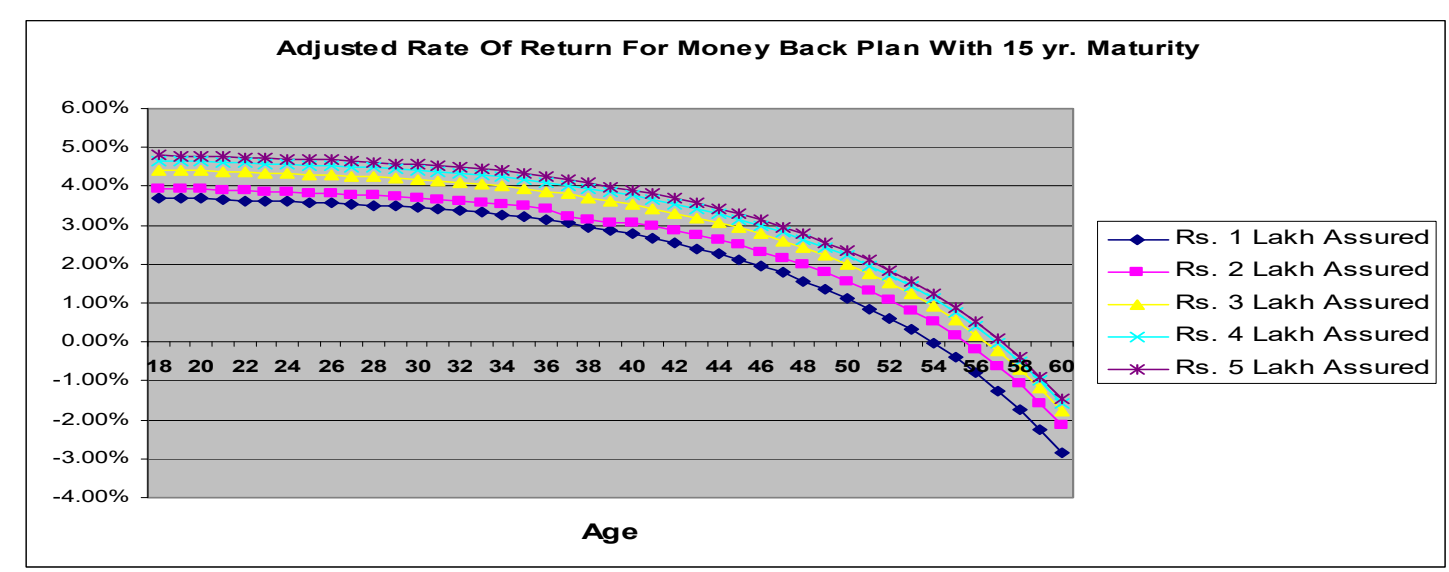

As noted before, the unadjusted and adjusted IRR curves for the Money Back Plan are observed to follow similar patterns, at different levels of sum assured, and across different maturity periods. For this policy, higher levels of sum assured are observed to give higher rates of return. The rates of returns are observed to decrease with age. The rate of decrease of rates of return with age is fast in all the cases, and hence the IRR curves in each case have a steep slope, becoming negative at certain ages. The IRR curves are almost parallel to each other, indicating that at different levels of sum assured the rates of return decrease at a uniform rate.

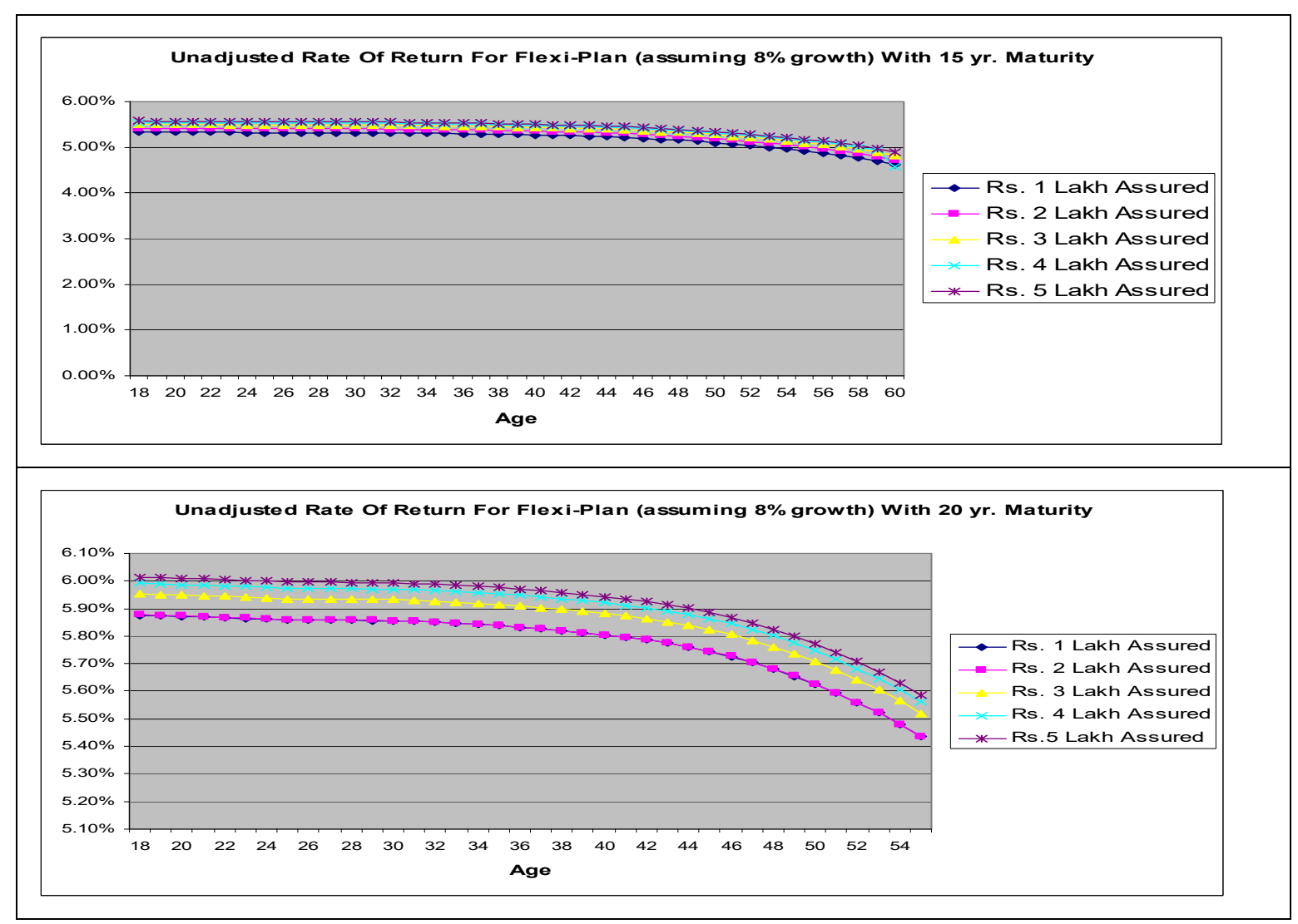



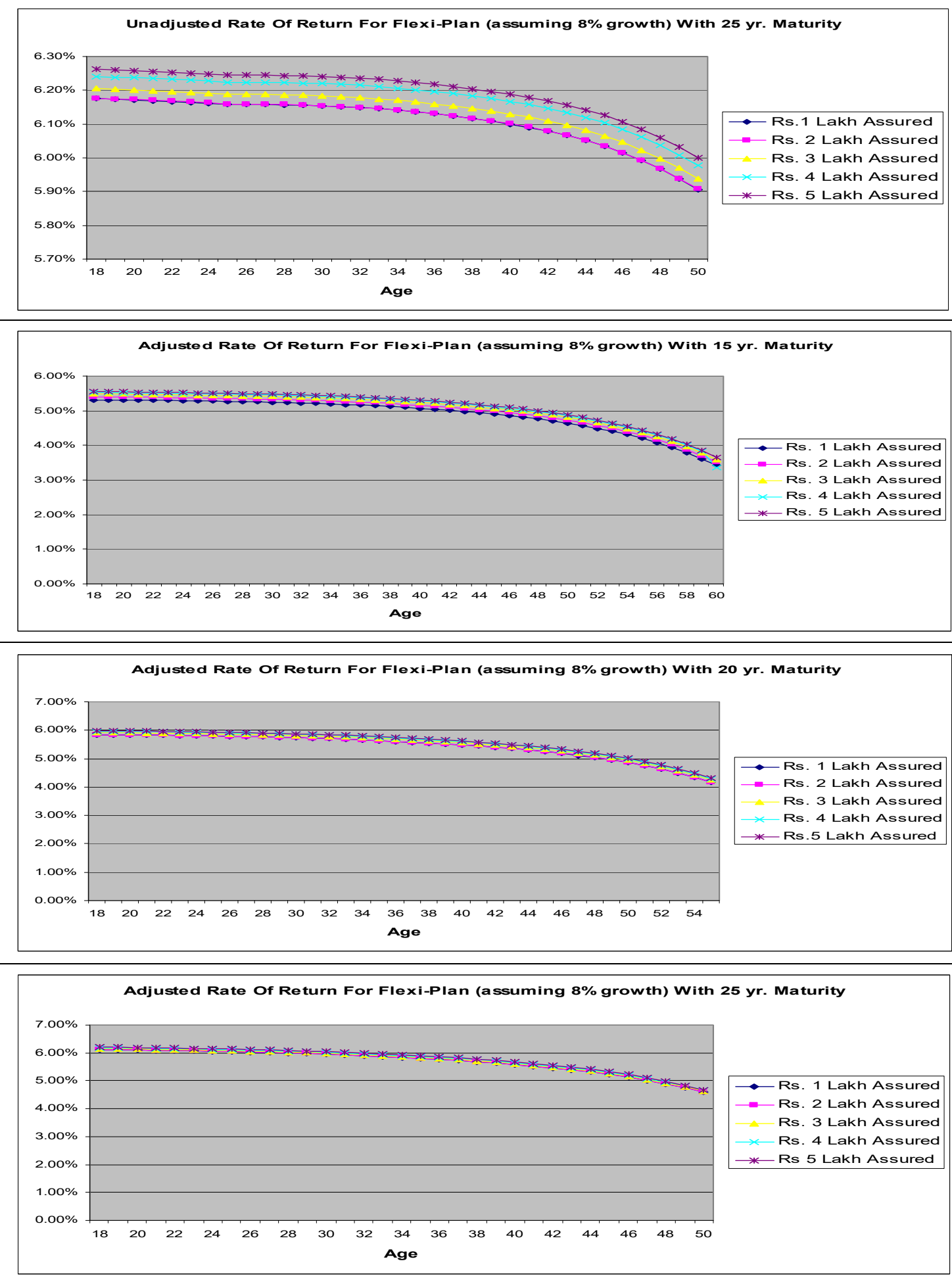


\section{Ml Macrothink}
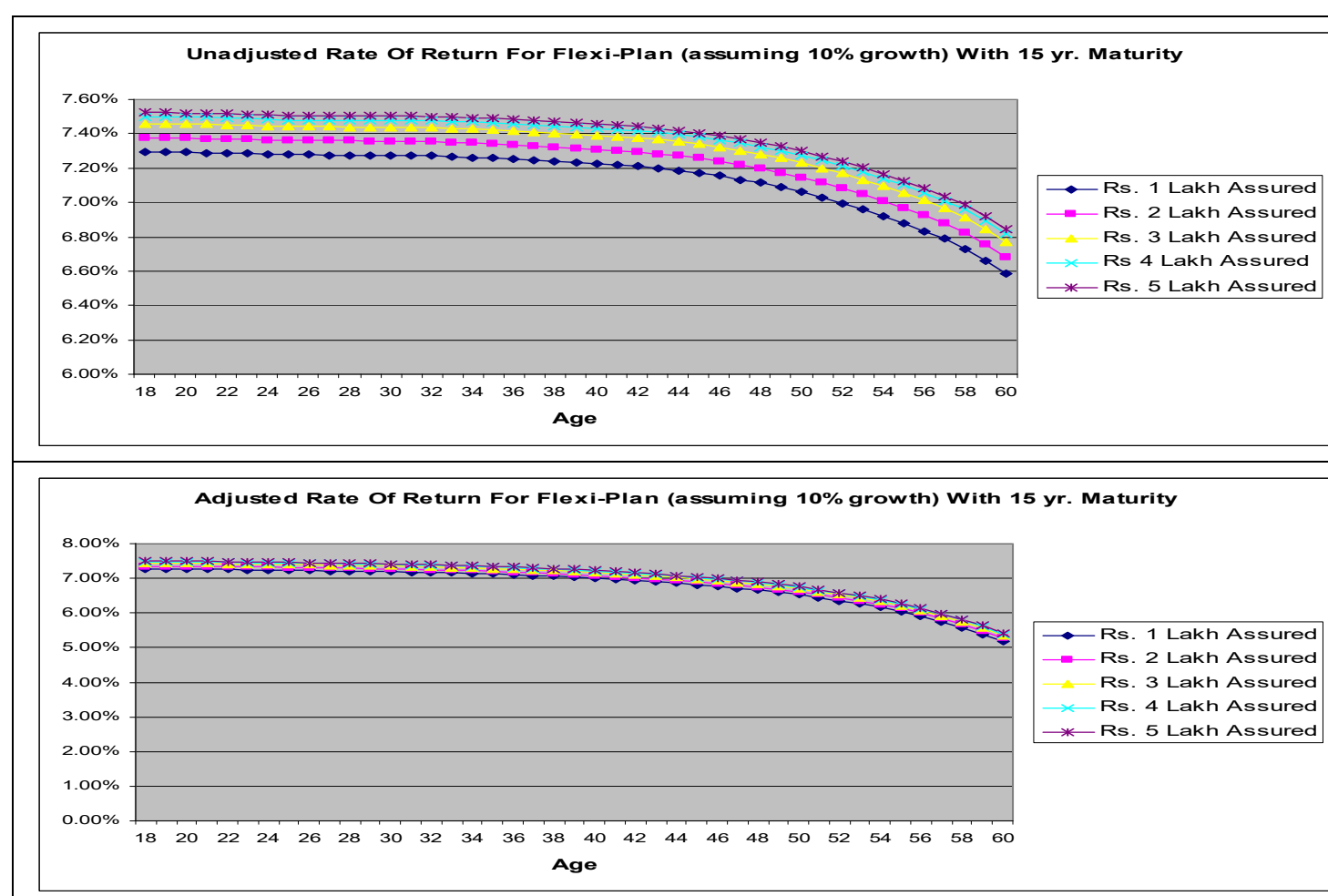

As noted before, the unadjusted and adjusted IRR curves for the Flexi-Plan (assuming 8\% growth) are observed to follow similar patterns, at different levels of sum assured, and across different maturity periods. It is observed that higher levels of sum assured give higher returns. The unadjusted IRR curves are almost parallel to each other, indicating that at different levels of sum assured, the rate of decrease of unadjusted rate of return with age follows a uniform pattern. Also, the unadjusted IRR curves at 20 and 25 year maturity periods have a steeper slope, indicating that the rate of decrease in unadjusted rate of return increases with maturity period. On the other hand, the adjusted IRR curves coincide together, indicating that at different levels of sum assured the differences between the adjusted rates of return are very small. A similar pattern is observed for the Flex-Plan (assuming 10\% growth), with even steeper slope.

\section{By Adjusted/ Unadjusted Rates}

The series of graphs which follow present a comparison of the adjusted and unadjusted rates of return for each policy at different levels of sum assured and at different maturity periods: 

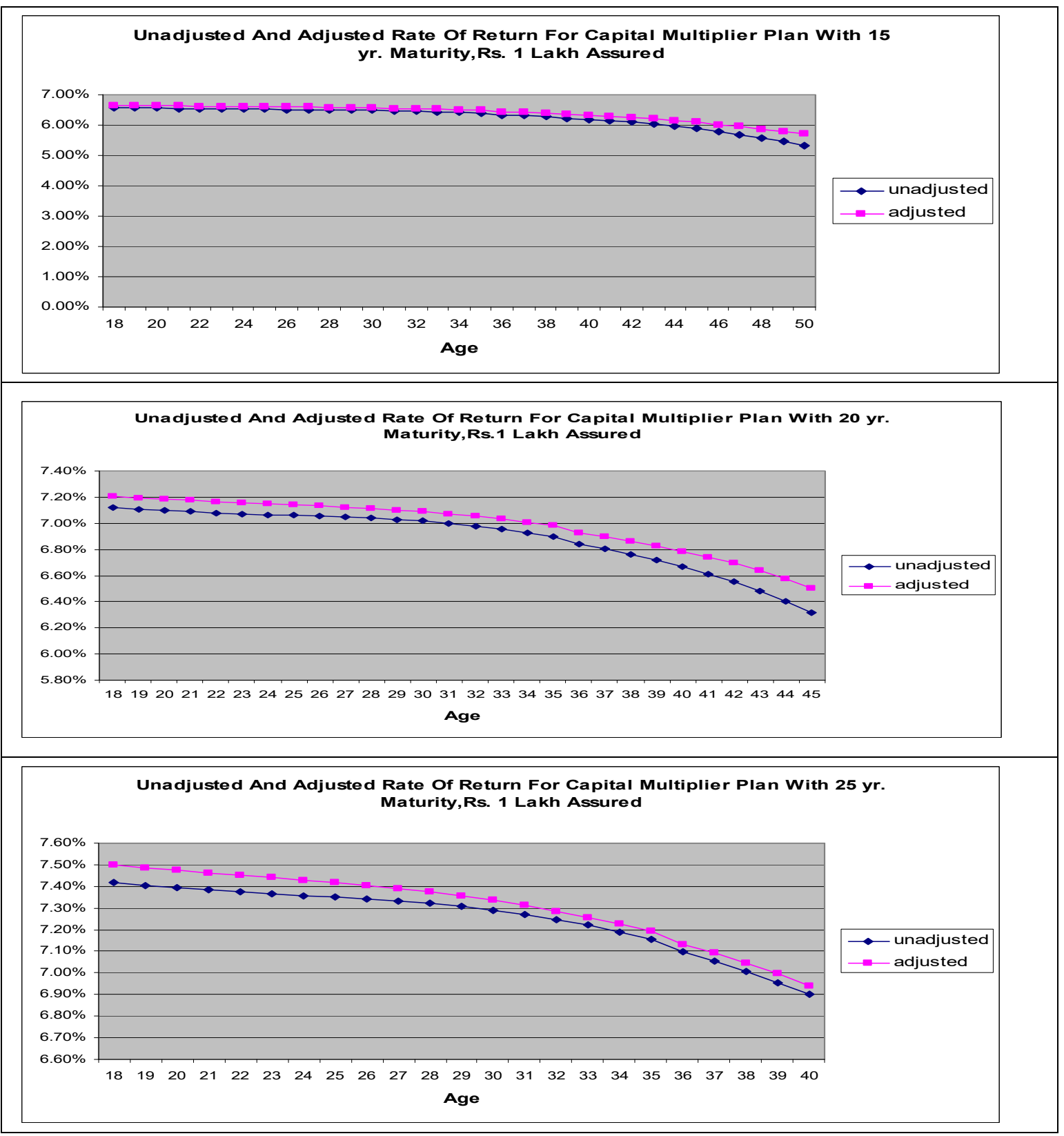

Again, the unadjusted and adjusted IRR curves for the Capital Multiplier Plan are observed to follow similar patterns, at different levels of sum assured, and across different maturity periods. It is observed that the adjusted rates of return are always higher than the unadjusted rates of return. However, in the case of 15 year maturity period, the difference between adjusted and unadjusted rates of return increases with age, while the difference between the adjusted and unadjusted rates of return is more in case of 20 year maturity period, remaining constant with age, and in the case of 25 year maturity period, the difference between the adjusted and unadjusted rates of return decreases with age. 


\section{Macrothink}

Asian Journal of Finance \& Accounting

ISSN 1946-052X

2016, Vol. 8, No. 2

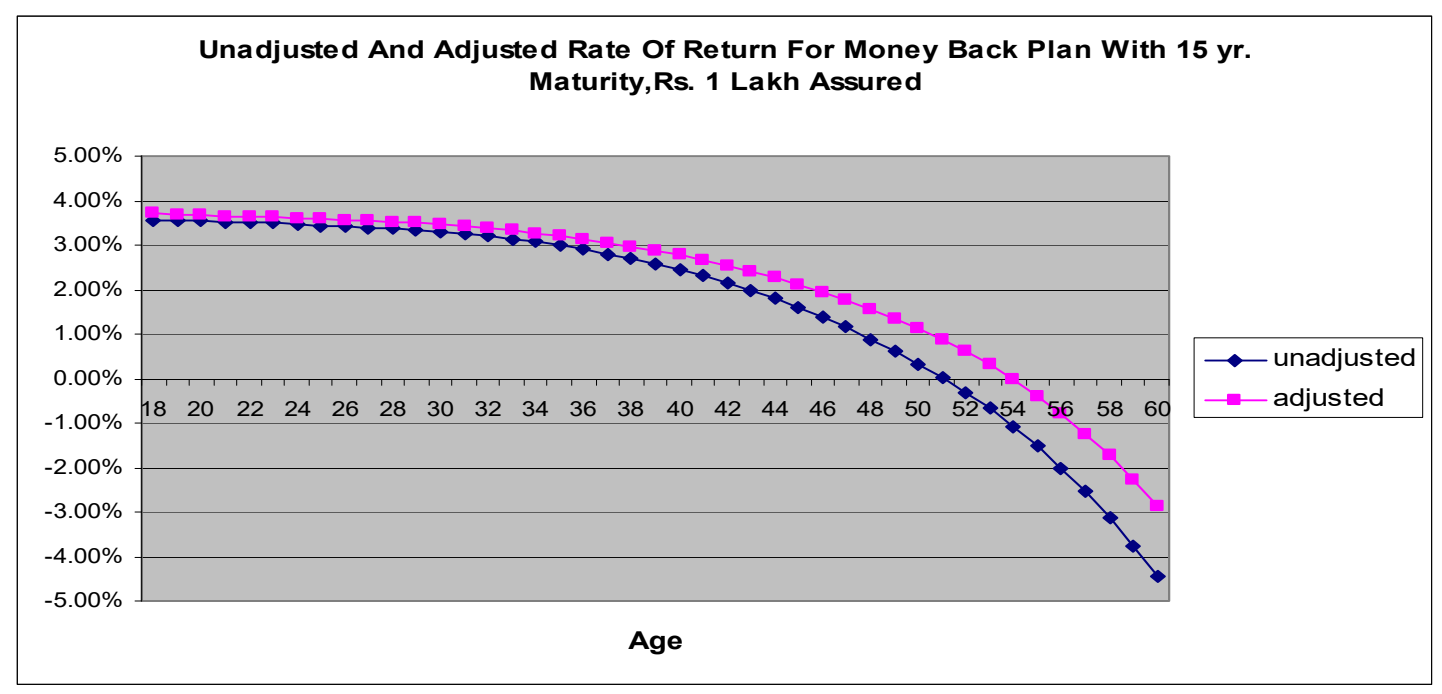

Again, the unadjusted and adjusted IRR curves for the Money Back Plan are observed to follow similar patterns, at different levels of sum assured, and across different maturity periods. It is observed that the adjusted rates of return are always higher than the unadjusted rates of return. In this case, however, the unadjusted and adjusted IRR curves are steeply downward sloping, and become negative at certain ages. The difference between adjusted and unadjusted rates of return rapidly increases with age.

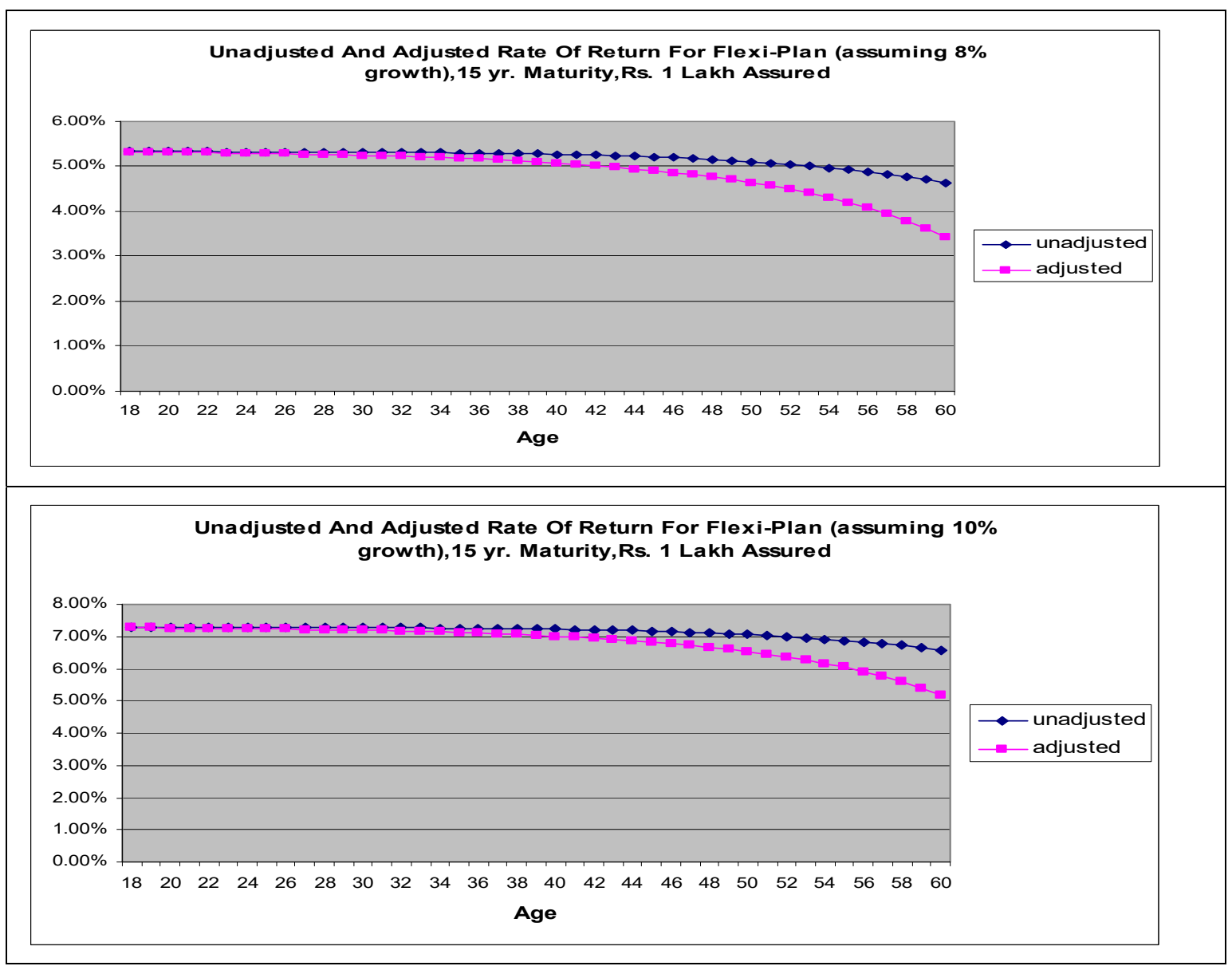




\section{Macrothink}

Asian Journal of Finance \& Accounting

ISSN 1946-052X

2016, Vol. 8, No. 2

Again, the unadjusted and adjusted IRR curves for the Flexi-Plan are observed to follow similar patterns, at different levels of sum assured, and across different maturity periods. It is observed that the adjusted rates of return are always lower than the unadjusted rates of return, in contrast to the Capital Multiplier Plan and the Money Back Plan, indicating that the Flexi-Plan is more of an investment plan. The difference between the adjusted and unadjusted rates of return rapidly increases beyond a certain age.

\section{Relationship Between Rates of Return}

Another type of comparison was made of the difference between adjusted and unadjusted rates of return for each policy, in which the probability of not surviving until the end of a particular contact (dependent on the maturity period; for example, for a 15 year maturity period, the probability of not surviving until the end of the $15^{\text {th }}$ year of the contract) was taken into consideration. In this case, both the unadjusted and adjusted rates of return were plotted against the probability of not surviving until the end of the particular contract, across different ages. The comparison for each type of policy is presented in the following series of graphs:

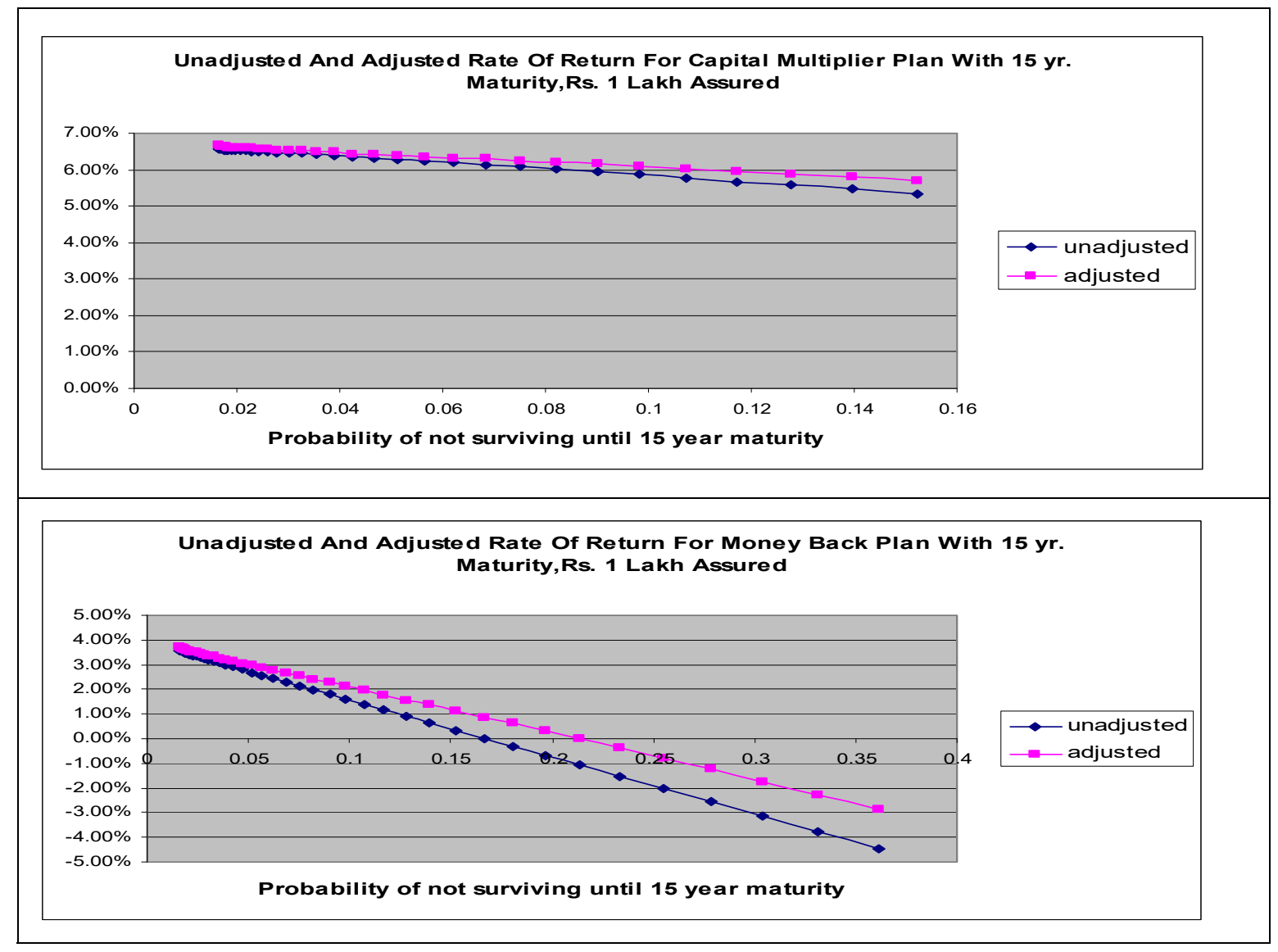



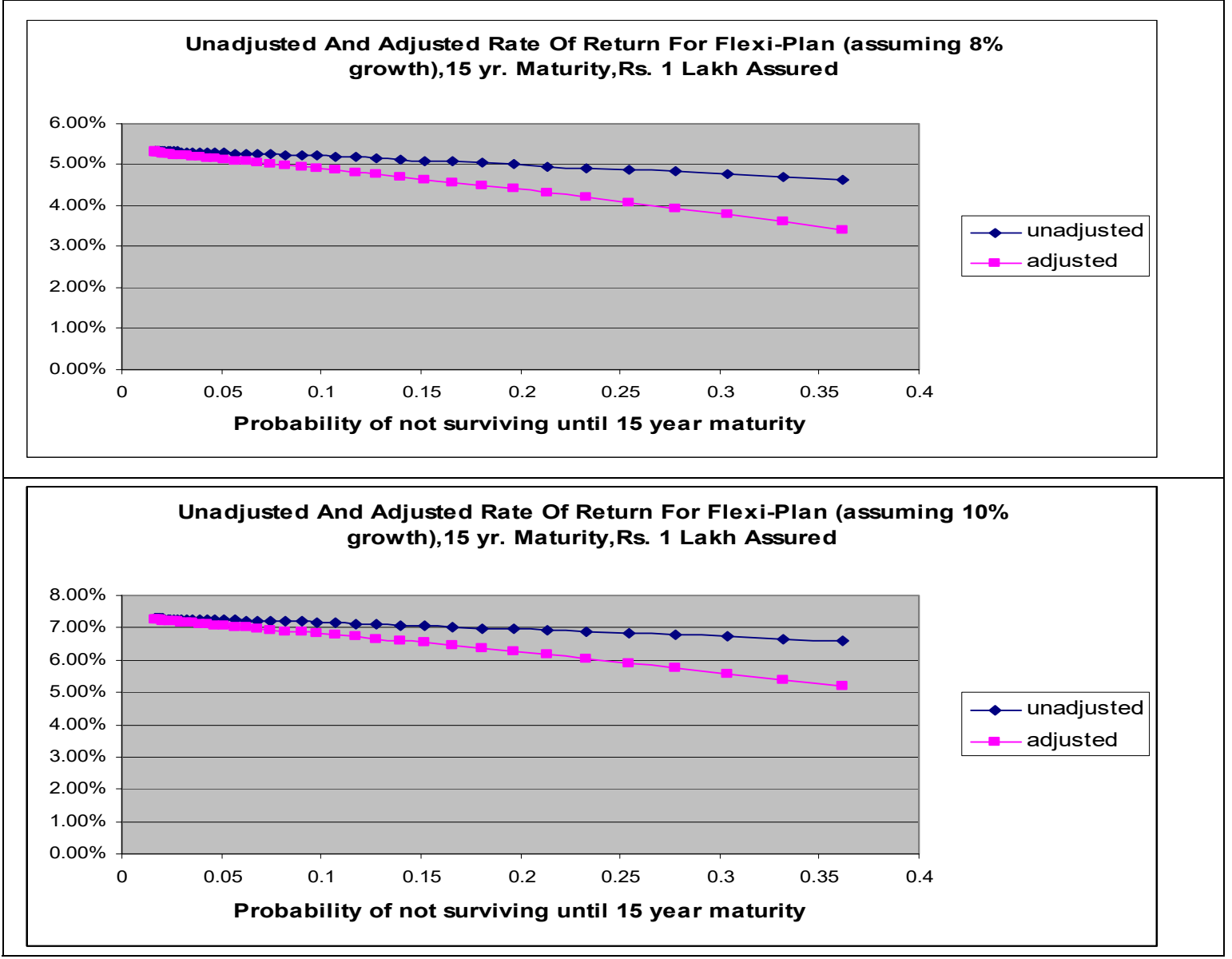

In all the cases, it was found that the unadjusted and adjusted rates of return follow a linear relationship. Using linear regression analysis, it was found that the mortality-adjusted rates of return and the unadjusted rates of return follow a relationship that is analogous to the capital asset pricing model (CAPM). This relationship can be expressed as follows:

$$
M A R R_{k, n}=U A R R_{k, n}+\beta \cdot x_{n}^{(k)}
$$

where $M A R R_{k, n}$ denotes the mortality adjusted rate of return, $U A R R_{k . n}$ the unadjusted rate of return, $x_{n}^{(k)}=\left(1-p_{n}^{(k)}\right)$ is the probability of a person aged $k$ not surviving until maturity $n$, and $\beta$ is the degree of responsiveness or sensitivity.

The regression coefficient $\beta$ could be interpreted as the increase in the discrepancy between unadjusted and mortality-adjusted rates of return with $1 \%$ increase in probability of not surviving until maturity. The unadjusted rate of return represents a "risk-free" rate of return, as individuals are assumed to survive until the end of the maturity period. Mortality 
represents a "systematic risk" which cannot be avoided, since it is influenced by external factors.

The $\beta$ values were computed at each level of maturity period and at each level of sum assured to find out how the degree of sensitivity varied with these factors. By taking the probability of not surviving until maturity as an independent factor and the adjustment term (mortality adjusted rate of return less unadjusted rate of return) to be a dependent factor, the relationship between them is analysed. In each case, they show a statistically significant linear relationship. Linear regression analysis through the origin gives the following $\beta$ values for each of the policies, as shown in Tables 1-4:

Table 1. $\beta$ values for the Capital Multiplier Plan

\begin{tabular}{|c|c|c|c|c|c|}
\hline & 1 lakh & 2 lakhs & 3 lakhs & 4 lakhs & 5 lakhs \\
\hline $\mathbf{1 5}$ yrs & 2.380 & 2.360 & 2.359 & 2.414 & 2.434 \\
\hline $\mathbf{2 0}$ yrs & 1.227 & 1.215 & 1.213 & 1.215 & 1.239 \\
\hline $\mathbf{2 5}$ yrs & 0.444 & 0.444 & 0.444 & 0.443 & 0.444 \\
\hline
\end{tabular}

Table 2: $\beta$ values for the Money Back Plan

\begin{tabular}{|c|c|c|c|c|c|}
\hline & 1 lakh & 2 lakhs & 3 lakhs & 4 lakhs & 5 lakhs \\
\hline $\mathbf{1 5}$ yrs & 4.809 & 4.961 & 5.074 & 5.132 & 5.168 \\
\hline $\mathbf{2 0}$ yrs & 3.440 & 3.500 & 3.602 & 3.656 & 3.689 \\
\hline $\mathbf{2 5}$ yrs & 1.620 & 1.633 & 1.706 & 1.750 & 1.778 \\
\hline
\end{tabular}

Table 3. $\beta$ values for the Flexi-Plan (assuming $8 \%$ growth)

\begin{tabular}{|l|c|c|c|c|c|}
\hline & 1 lakh & 2 lakhs & 3 lakhs & 4 lakhs & 5 lakhs \\
\hline $\mathbf{1 5}$ yrs & -3.165 & -3.190 & -3.214 & -3.212 & -3.233 \\
\hline $\mathbf{2 0}$ yrs & -3.009 & -3.009 & -3.028 & -3.038 & -3.043 \\
\hline $\mathbf{2 5}$ yrs & -2.974 & -2.974 & -2.980 & -2.988 & -2.993 \\
\hline
\end{tabular}

Table 4. $\beta$ values for the Flexi-Plan (assuming 10\% growth)

\begin{tabular}{|l|c|c|c|c|c|}
\hline & 1 lakh & 2 lakhs & 3 lakhs & 4 lakhs & 5 lakhs \\
\hline $\mathbf{1 5}$ yrs & -3.677 & -3.700 & -3.722 & -3.733 & -3.740 \\
\hline $\mathbf{2 0}$ yrs & -3.413 & -3.413 & -3.430 & -3.438 & -3.443 \\
\hline $\mathbf{2 5}$ yrs & -3.298 & -3.298 & -3.304 & -3.310 & -3.314 \\
\hline
\end{tabular}




\section{Macrothink}

Asian Journal of Finance \& Accounting

ISSN 1946-052X 2016, Vol. 8, No. 2

It is observed that, in almost all the cases, at each level of maturity period, the degree of sensitivity increases as the level of sum assured increases, and that the degree of sensitivity is higher at lower maturity periods, i.e. the sensitivity decreases as maturity period increases. Further, the Money Back Plan shows the highest degree of sensitivity and the Capital Multiplier Plan shows the lowest degree of sensitivity. In fact, the $\beta$ values for the Capital Multiplier Plan show an anomalous trend with the level of sum assured. Finally, the Flexi-Plan (assuming 10\% growth) shows a higher degree of sensitivity than the Flexi-Plan (assuming 8\% growth).

Finally, in order to understand how the degree of sensitivity varied with the level of sum assured and the maturity period for each policy, a second-stage regression was performed for the $\beta$ values on the level of sum assured and the maturity. The results of the second-stage regression are shown in Tables 5-8:

Table 5. $\beta$ Regression for the Capital Multiplier Plan

\begin{tabular}{cccc}
\hline & coefficient & t stat & p-value \\
\hline intercept & 5.2244 & 35.7489 & 0.0000 \\
sum assured & 0.0000 & 0.3241 & 0.7514 \\
maturity & -0.1946 & -29.5201 & 0.0000 \\
\hline
\end{tabular}

\begin{tabular}{cccccc}
\multicolumn{1}{c}{ ANOVA } & $\boldsymbol{d} \boldsymbol{f}$ & $\boldsymbol{S S}$ & $\boldsymbol{M S}$ & $\boldsymbol{F}$ & Significance $\boldsymbol{F}$ \\
\hline Regression & 2 & 9.4645 & 4.7323 & 435.7720 & 0.0000 \\
Residual & 12 & 0.1303 & 0.0109 & & \\
Total & 14 & 9.5949 & & \\
\hline \multicolumn{2}{c}{} \\
\multicolumn{2}{c}{ Regression Statistics } \\
Multiple R & $99.32 \%$ & & & \\
R Square & $98.64 \%$ & & & \\
Adjusted R Square & $98.42 \%$ & & & \\
\hline
\end{tabular}


Table 6. $\beta$ Regression for the Money Back Plan

\begin{tabular}{cccc}
\hline & coefficient & t stat & p-value \\
\hline intercept & 9.8997 & 59.0512 & 0.0000 \\
sum assured & 0.0000 & 3.0178 & 0.0107 \\
maturity & -0.3331 & -44.0623 & 0.0000 \\
\hline
\end{tabular}

ANOVA

\begin{tabular}{cccccc}
\hline & $\boldsymbol{d} \boldsymbol{f}$ & $\boldsymbol{S S}$ & $\boldsymbol{M S}$ & $\boldsymbol{F}$ & Significance $\boldsymbol{F}$ \\
\hline Regression & 2 & 27.8757 & 13.9379 & 975.2989 & 0.0000 \\
Residual & 12 & 0.1715 & 0.0143 & & \\
Total & 14 & 28.0472 & & & \\
\hline
\end{tabular}

Regression Statistics

Multiple R $\quad 99.69 \%$

R Square $\quad 99.39 \%$

Adjusted R Square $\quad 99.29 \%$

Table 7. $\beta$ Regression for the Flexi-Plan (assuming $8 \%$ growth)

\begin{tabular}{cccc}
\hline & coefficients & t stat & p-value \\
\hline intercept & -3.4813 & -68.4262 & 0.0000 \\
sum assured & 0.0000 & -1.5450 & 0.1483 \\
maturity & 0.0221 & 9.6318 & 0.0000 \\
\hline
\end{tabular}

ANOVA

\begin{tabular}{cccccc}
\hline & $\boldsymbol{d} \boldsymbol{f}$ & $\boldsymbol{S S}$ & $\boldsymbol{M S}$ & $\boldsymbol{F}$ & Significance $\boldsymbol{F}$ \\
\hline Regression & 2 & 0.1252 & 0.0626 & 47.5795 & 0.0000 \\
Residual & 12 & 0.0158 & 0.0013 & & \\
Total & 14 & 0.1410 & & & \\
\hline
\end{tabular}

\section{Regression Statistics}

$\begin{array}{cc}\text { Multiple R } & 94.23 \% \\ \text { R Square } & 88.80 \% \\ \text { justed R Square } & 86.94 \%\end{array}$

Adjusted R Square $\quad 86.94 \%$ 
Table 8. $\beta$ Regression for the Flexi-Plan (assuming 10\% growth)

\begin{tabular}{cccc}
\hline & coefficient & t stat & p-value \\
\hline intercept & -4.2726 & -68.9861 & 0.0000 \\
sum assured & 0.0000 & -1.1906 & 0.2568 \\
maturity & 0.0410 & 14.6644 & 0.0000 \\
\hline
\end{tabular}

ANOVA

\begin{tabular}{cccccc}
\hline & $\boldsymbol{d} \boldsymbol{f}$ & $\boldsymbol{S S}$ & $\boldsymbol{M S}$ & $\boldsymbol{F}$ & Significance $\boldsymbol{F}$ \\
\hline Regression & 2 & 0.4222 & 0.2111 & 108.2311 & 0.0000 \\
Residual & 12 & 0.0234 & 0.0020 & & \\
Total & 14 & 0.4456 & & & \\
\hline
\end{tabular}

\begin{tabular}{cc}
\hline \multicolumn{2}{c}{ Regression Statistics } \\
\hline Multiple R & $97.34 \%$ \\
R Square & $94.75 \%$ \\
Adjusted R Square & $93.87 \%$ \\
\hline
\end{tabular}

For the Capital Multiplier Plan, it was found that the level of sum assured has no statistically significant effect on the degree of sensitivity, while the maturity period has a statistically significant negative effect on the degree of sensitivity. For the Money Back Plan, however, it was found that the level of sum assured has a statistically significant positive effect on the degree of sensitivity, while the maturity period has a statistically significant negative effect on the degree of sensitivity. Finally, for the Flexi-Plan(s), it was found that the level of sum assured has no statistically significant effect on the degree of sensitivity, while the maturity period has a statistically significant positive effect on the degree of sensitivity. All the regressions are statistically significant, explaining about $90 \%$ or more of the variation in the degree of sensitivity.

\section{Discussion}

The primary objective of the study was to analyse and compare the pattern of adjusted and unadjusted rates of return for different types of policies. From these comparisons, the following were the key findings:

- For each type of policy, in each type of comparison made for unadjusted rates of return, the IRR curves follow similar patterns.

- For each type of policy, in each type of comparison made for mortality-adjusted rates of return, the IRR curves follow similar patterns.

- In the comparison based on sum assured made separately for unadjusted and adjusted rates of return for each specific policy, it was found that, for the Capital Multiplier Plan and Money Back Plan, the unadjusted and mortality-adjusted rates of return follow similar patterns, while for the Flexi-Plan they do not follow similar patterns. For other types of comparisons, the unadjusted and adjusted rates of return follow similar patterns. 


\section{Macrothink}

- Higher maturity periods tend to give higher rates of return in the case of Capital Multiplier Plan and the Flexi-Plan, but the reverse is true in the case of the Money Back Plan.

- For each type of policy, higher levels of sum assured tend to give higher levels of rates of return.

- In the comparisons between unadjusted and mortality-adjusted rates of return, the adjusted rates of return are higher than unadjusted rates of return in the case of Capital Multiplier Plan and Money Back Plan, but, in the case of Flexi-Plan, the unadjusted rates of return are higher.

- It was found that the difference between unadjusted and mortality-adjusted rates of return follow a linear relationship against the probability of not surviving until the end of the contact that is very similar to the capital asset pricing model. This linear relationship introduces a natural notion of the sensitivity of the rates of return to mortality. It was found that the Money Back Plan showed the highest degree of sensitivity.

- It was found that the linear relationship could be extended to include the effects of the level of sum assured and the maturity period on the sensitivity, specific to a (type of) policy.

As a result of the above analyses, it is possible to propose a model for the relationship between the adjusted and unadjusted rates of return, specific to a policy (or type of policy), as follows:

$$
M A R R_{k, n}=U A R R_{k, n}+\left(\beta_{0}+\beta_{1} \cdot S A+\beta_{2} \cdot n\right) x_{n}^{(k)}
$$

where $M A R R_{k, n}$ is the mortality adjusted rate of return, $U A R R_{k . n}$ is the unadjusted rate of return, $x_{n}^{(k)}=\left(1-p_{n}^{(k)}\right)$ is the probability of a person aged $k$ not surviving until maturity $n$, $\beta_{j}$ 's are the degrees of responsiveness or sensitivity, and $S A$ is the level of sum assured.

It is to be noted that the model above only specifies a relationship between the adjusted and unadjusted rates of return, and does not specify a model for unadjusted rates of return. As earlier results had suggested, the adjusted and unadjusted rates of return follow a linear relationship with the probability of not surviving until the end of the contract, mediated by the parameters of the level of sum assured and the maturity period. A similar linear regression analysis would yield a model for unadjusted rates of return in terms of these same variables. However, this is beyond the scope of the present study, and would be an interesting direction for further research.

The study does suffer from a few limitations. Firstly, only three life insurance policies were considered in the analysis and that too from only one life insurance company, viz. Kotak Mahindra Old Mutual Life Insurance Limited. A more extensive study of a larger number and different types of policies would be required to confirm the generalisability of the results. 


\section{Macrothink

Another limitation of the study is the reliance on LIC mortality tables, which are known to be somewhat outdated, though they are used by practically all life insurance companies even to date. Moreover, the mortality rates used are generalised rates and there is always a possibility that these rates may differ for different categories of individuals. Such considerations may be incorporated in the methodology in a straightforward manner to yield richer results.

Finally, a point to be noted here is that the study took into consideration mortality risk only. Life insurance contracts may involve many other risks besides the major risk of mortality. As such, the methodology used in the study did not take into account other risk factors. The study opens a further scope of research to include other risk factors which may be relevant in addition to the risk of mortality.

\section{References}

Brealey, R.A., \& Myers, S.C. (1996). Principles of Corporate Finance (5 ${ }^{\text {th }}$ Ed.) McGraw-Hill.

Feldblum, S. (1992). Pricing Insurance Policies: The Internal Rate of Return Model. Study Note, Casualty Actuarial Society. Available at: www.casact.org/library/studynotes/feldblum9.pdf

Myers, S.C., \& Cohn, R.A. (1987). A Discounted Cash Flow Approach to Property-Liability Insurance Rate Regulation. Fair Rate of Return in Property-Liability Insurance, Klower-Nijhoff. http://dx.doi.org/10.1007/978-94-015-7753-3_3

Teufel, P., Tongson, T.J., \& Rech, J.E. (2001). Insurance Risk 101, Technical Report, American Academy of Actuaries, Washington D.C. 